\title{
Práticas científicas e colonialismo tardio em Portugal: acerca da (in)visibilidade de género em narrativas sobre quotidianos asiáticos*
}

\author{
Ema Ribeiro Pires** \\ Maria de Fátima Nunes***
}

\section{Resumo}

Este artigo explora relações entre género, prática científica $e$ representações do espaço entre académicos portugueses que trabalham na Ásia. O foco empírico é colocado na análise da prática científica de uma cientista social, Graciete Batalha, com vista a discutir o seu trabalho em comparação com outras narrativas académicas suas contemporâneas. No verão de 1974, a linguista Graciete Batalha viaja para a cidade de Malaca (Malásia) numa missão científica de aplicação de um inquérito linguístico a uma população local, a qual é caracterizada como tendo origem portuguesa. Argumentamos que o trabalho dessa linguista se posiciona numa transição entre dois diferentes modos de produção de conhecimento, o colonial e o pós-colonial.

Palavras-chave: Ásia, Género, Prática Científica, Colonialismo, Portugal.

* Recebido em 7 de março de 2016, aceito em 17 de outubro de 2016.

** Professora auxiliar da Universidade de Évora, Évora, Portugal, pesquisadora do Instituto de História Contemporânea, Portugal, e pesquisadora colaboradora da Universidade de Brasília (PPGAS-DAN), Brasilia, Brasil. epires@uevora.pt *** Professora Catedrática no Departamento de História, Universidade de Évora, Évora, pesquisadora do Instituto de História Contemporânea, Portugal. mfn@uevora.pt 
Scientific Practices and Late Colonialism in Portugal: on Gender

(In)visibility in Daily-life narratives on Asia

\begin{abstract}
This article explores relations between gender, scientific practice and representations of space among portuguese academics working in Asia. Empirical focus is put in analising academic narratives of one woman social scientist, Graciete Batalha, in order to discuss it in comparison with other contemporary scientific narratives. In the summer of 1974, linguist Graciete Batalha travels to West Malaysia in a scientific mission to Malacca to apply a linguistic inquiry to a local population of Portuguese origin. We argue that her work is in a position of transition between two different modes of knowledge production, the colonial and the postcolonial.
\end{abstract}

Keywords: Asia, Gender, Scientific Practice, Colonialism, Portugal. 
A fundamental part of Eurocentrism is the ideological construction of the "Orient"

Syed F. Alatas (2006:45).

Este texto é motivado por uma indagação $e$ uma curiosidade em questionar a invisibilidade das mulheres entre os actores envolvidos na produção de conhecimento científico sobre a Ásia, o Sudeste Asiático, e, concretamente, a cidade de Malaca (na Malásia Ocidental) em trabalhos académicos realizados a partir de Portugal, e/ou publicados em Portugal. Este ensaio, realizado no contexto de um diálogo disciplinar entre antropologia e história da ciência, foca-se assim na compreensão da relação entre práticas académicas e género. Louise Lamphere, Helena Ragoné e Patrícia Zavella, citando Di Leonardo (1991:28-32), defendem que o género é

historicamente contingente e construído, simultaneamente imbricado em condições materiais, instituições sociais, $e$ significados culturais. Finalmente, o género está intimamente vinculado a desigualdades, não apenas na usual relação de dominação de homens sobre mulheres, mas também nas relações de classe e raça (Lamphere et al., 1997:4). ${ }^{1}$

A construção social do género é um processo que tem na ciência alguns dos seus recortes mais visíveis. A praxis científica, como outras dimensões do mundo social, é regida por princípios de produção de ideologias de género que evidenciam a centralidade dominante da figura masculina do cientista $e$

1 Tradução nossa do original em que se lê que o género é "historically contingent and constructed, simultaneously embedded in material relations, social institutions, and cultural meanings. Finally, gender is intimately bound up with inequalities, not only in the often dominant relation of men to women but also to those of class and race" (Lamphere et al., 1997:4). 
invisibilizam ou secundarizam as mulheres cientistas. Tomamos aqui o gênero na sua leitura ampla, enquanto tipo de diferenciação categorial (Strathern, 2006:19) e partimos do contexto empírico de produção de Graciete Nogueira Batalha, uma académica educada em Portugal que viveu e trabalhou em contextos asiáticos na transição entre o ocaso do mundo colonial $e$ a instauração da democracia em Portugal.

\section{Puzzles académicos: "Malaca" na Biblioteca Nacional de Portugal}

Metodologicamente, ancoramos esta pesquisa em pesquisa bibliográfica e documental e em observação directa (durante 11 meses), na cidade de Malaca. Deambulámos à procura de Malaca nas estantes da Biblioteca Nacional de Portugal (em 2007-2008 e 2016). As referências no catálogo misturam narrativas literárias (as muitas cópias de Emílio Salgari sobre Tarzan) com outras, académicas. A grelha de leitura mostrou-nos que as narrativas ora elucidam ora obscurecem a realidade. A viagem bibliográfica até Malaca mostrou-me, não obstante, como a ironia e a ficção iluminam os caminhos do conhecimento. A revisão crítica da bibliografia aqui apresentada tem uma baliza concreta: a produção académica portuguesa indexada na PORBASE (e, concretamente, no acervo da Biblioteca Nacional de Portugal), por palavra-chave "Malaca". A categorização com base no critério geográfico é problemática, mas assume-se, para já, esse critério. A atmosfera intelectual do fim do século XIX, do romantismo de ventos orientalistas, reclamando o império colonial reajustado pós Berlim e o ultimato inglês a Portugal, são o cenário de partida para se compreender a demanda da Ásia pela academia portuguesa. Adicionalmente, a Sociedade de Geografia de Lisboa, criada em 1875 , vem dar um impulso adicional à reflexão científica sobre a aquele continente. Durante o século XX e o período do Estado Novo em Portugal, várias instituições se evidenciam enquanto lugares de produção científica de onde se olhava a Ásia².

2 O Instituto Superior de Ciências Sociais e Políticas (ISCSP), criado em 1906 (com uma outra designação), foi um dos lugares de cartografia do autodesignado 
Um estudo pioneiro, referência incontornável na análise sociolinguística e etnográfica do Bairro Português de Malaca, é a obra de António da Silva Rêgo, O Dialecto Português de Malaca e Outros Escritos (publicada em 1942, e entretanto reeditada pela Comissão Nacional para as Comemorações dos Descobrimentos de Portugal, em 1998). Esse trabalho compila um conjunto de textos dispersos, publicados pelo autor no Boletim Eclesiástico da Diocese de Macau, durante a década de 1930. Globalmente, a obra de Silva Rego permite retraçar alguns dos momentos de interacção entre a comunidade portuguesa de Malaca e Portugal durante o século XX. Adicionalmente, a sua obra acaba por ser uma metáfora do modo de produção de conhecimento científico colonial sobre aquele lugar e, mais abrangentemente, sobre a Ásia. Após 1974, entre continuidades e rupturas, começam a efectivar-se transições para um modo de produção de conhecimento científico da contemporaneidade, que ainda assim, parece ter algumas resistências e anacronismos. É nesse contexto de transição que surge a autora que nos ocupa neste texto.

\section{A discípula de Boléo "entre o hospitaleiro povo do Kampong Portugis"}

Entre os estudos linguísticos e sociolinguísticos realizados durante a segunda metade do século $\mathrm{XX}$, produzidos pela comunidade académica que escreve a partir de Portugal, assume especial relevância a análise de Graciete Nogueira Batalha pela sua condição humana e pelo que recolhe de relevante para compreendermos os interstícios do quotidiano de Malaca em 1974.

Das narrativas biográficas fixadas ${ }^{3}$ em torno de Graciete Nogueira Batalha (Aresta, 2001, 2010; Graciete Batalha, 1995)

império português. Lugar de ensino e de formação de quadros para o espaço colonial, foi também espaço pioneiro de ensino de ciências sociais no país, em contexto de ciência colonial (cf. Barata 1996). Outras instituições eram o Instituto de Alta Cultura, também o Instituto Histórico Ultramarino, a Agência Geral do Ultramar e a Sociedade de Geografia.

3 Graciete Agostinho Nogueira nasceu na cidade de Leiria, a 30 de Janeiro de 1925. Frequentou o Liceu de Rodrigues Lobo, em Leiria, e em Coimbra o 
discorre um capital social $e$ científico validado a Oriente $e$ disseminado a partir de um ponto da Ásia - Macau - sob administração portuguesa do Estado Novo, e também na Democracia - para a Europa dos filólogos e dos linguistas.

Dessa autora, é central o texto "O Inquérito Linguístico Boléo em Malaca. O Chão de Padre e seus Moradores Portugueses", publicado em 1981 numa obra de homenagem ao linguista M. Paiva Boléo, e reeditado em 1986 pela Imprensa Oficial de Macau, com o título "Malaca: O Chão de Padre e Seus Moradores 'Portugueses'". Igualmente relevante é o artigo "Situação e Perspectivas do Português e dos Crioulos de Origem Portuguesa na Ásia Oriental (Macau, Hong Kong, Malaca, Singapura, Indonésia)" (1985), produzido como comunicação ao Congresso sobre a Situação actual da Língua Portuguesa no Mundo, em 1983, e publicado como separata às Actas do referido congresso. Importa mergulhar nos conteúdos que a autora delega à academia, alguns dos quais com informação etnográfica $e$ metodológica relevante para a presente investigação.

Graciete Nogueira Batalha produz o artigo de 1981, "O Inquérito Linguístico Boléo em Malaca. O Chão de Padre e seus

Infanta D. Maria. Ingressa na Faculdade de Letras da Universidade de Coimbra, licenciando-se em Filologia Clássica em 1949. Nesse ano casa com colega do curso de Medicina, de origem Macaense - José Marcos Batalha, partindo para Macau, onde Graciete assume o nome profissional de Graciete Batalha ou Graciete Nogueira Batalha. Em Macau iniciou sua carreira como professora da Escola Primária Oficial, desde 1949 até 1957. Convidada a dar aulas na Universidade de Hongkong, ensinou lá Língua Portuguesa, em 1958-1959. Mas foi no Liceu Nacional Infante D. Henrique que fez grande parte do seu percurso de docente, terminando a sua carreira no dia 15 de Julho de 1985. Assumiu também as funções de Diretora da Escola do Magistério Primário entre 1967 a 1969. Professora e pedagoga, conferencista, linguista, ensaísta e publicista atributos que biógrafos lhe atribuem. Foi membro do Conselho Legislativo de Macau, da Assembleia Legislativa de Macau e do Conselho Consultivo do Governador de Macau. Como corolário do reconhecimento do seu trabalho foi agraciada com o grau de Oficial da Ordem do Império (1973) e com a Medalha de Mérito Cultural (1984). Recebeu o Prémio Camilo Pessanha em 1991, atribuído pelo Instituto Português do Oriente. Foi membro da Sociedade de Geografia de Lisboa (Aresta, 2001; 2010; Graciete Batalha, 1995). 
Moradores Portugueses", com base numa viagem de uma semana de pesquisa intensiva a Malaca, realizada em agosto de 1974. Financiada pelo Governo de Macau, era motivada pelo objectivo de estudar "a proveniência de uma boa centena de vocábulos macaenses" (Batalha, 1981:25). Porém, confessa a linguista, o "vírus do inquérito linguístico" levou-a a aplicar, com alterações, o inquérito linguístico Boléo (I.L.B.) à comunidade, tendo em conta os constrangimentos temporais $e$ "o contexto social inteiramente diferente do das vilas e aldeias de Portugal" (Batalha, 1981:25). A investigadora descreve com algum pormenor os aspectos relacionados com o acesso à informação, efectivado com recurso a patrocinato:

Tendo contactado previamente os padres da Missão Portuguesa de Malaca, Reverendos Manuel Pintado e Augusto Sendim, que foram incansáveis na assistência que me prestaram, eles me indicaram os informadores mais aptos e mais dispostos a colaborar.

Alguns dos aspectos metodológicos do processo de recolha de dados do inquérito são também explicitados, como por exemplo a relação com uma informante privilegiada, as dificuldades de recolha e triangulação dos dados, assim como os constrangimentos de tempo e condições climáticas encontrados pela linguista (Batalha, 1981:27):

No caso particular do presente inquérito, uma mulher ${ }^{4}$ de pescador, de 36 anos, revelou-se de facto uma óptima informadora, com plena compreensão dos meus objectivos e extraordinária boa vontade. Pena foi que, sendo doméstica e não colaborando no trabalho do marido, o seu

${ }^{4} \mathrm{O}$ nome da informante não é identificado. Porém, por meio das fotografias anexas ao texto que mostram a habitação, $e$ autora $e$ informante com familiares desta última, parece-me que o nome não identificado por Batalha, pode ser Teresa da Costa. Em entrevista informal a Sub de Costa (filho de Teresa da Costa), em 19 Agosto de 2006, ele mencionou o apelido da linguista ao evocar a passagem de one lady from Macao pelo bairro e pela casa da sua família. 
conhecimento dos objectos e utensílios relativos à pesca ocupação normal dos homens, e só dos homens da comunidade - era muito limitado. E o marido, apesar de o inquérito ser feito na sua própria casa, nunca compareceu e de nada informou.

Por isso, na parte II referente ao trabalho - PESCA E UTENSÍLIOS - apenas apresento uma escassa dúzia de respostas. Estando já no fim da minha estadia, esgotada por muitas horas seguidas de trabalho em péssimas condições climáticas (o calor e a humidade são talvez piores do que em Macau) não me foi possível interrogar sobre esse assunto outros informadores. Nem isso seria, pareceu-me, de grande proveito, pois desse pequeno número de respostas logo se deduz que a maioria dos termos referentes à pesca são malaios, como é natural numa actividade piscatória que já nada tem a ver com Portugal.

Ainda no decorrer do texto é feita uma descrição da cidade (Batalha, 1981:28), que quase poderia ser tom discursivo de uma narrativa de viagens, dirigida a um público lusófilo ${ }^{5}$ :

Para um português, sobretudo um português que viva em Macau, uma visita a Malaca é um regresso a eras passadas. Frente ao estreito de Malaca, contemplando o local onde os nossos homens desembarcaram para a conquista da terra, em 1511, lá está ainda o velho pórtico da fortaleza construída por Afonso de Albuquerque e seus capitães.

Segue-se uma paragem nos principais monumentos do património (colonial) da cidade (Batalha, 1981:29):

\footnotetext{
5 A imagem de arcaísmo da cidade (comparativamente a Macau), produzida pela autora, deixa nas entrelinhas da leitura do seu texto a suposição de um certo tom discursivo nostálgico (e de certo modo lusocêntrico) subjacente nas suas palavras.
} 
Vamos ao Museu de Malaca e vemos, em lugar de destaque, gravuras antigas com retratos de Afonso de Albuquerque, Diogo Lopes de Sequeira ou outros, ou com reconstituições da fortaleza; velhos trajos nobres do século $\mathrm{XVI}$, oferecidos pelo governo português, em manequins de tamanho natural; armas portuguesas, móveis portugueses, $e$ outros objectos de tempos idos que não se encontram em Macau.

Claro que também há artigos malaios, chineses, holandeses. Mas vendo o carinho com que coisas nossas são aí preservadas, volve-se-nos o pensamento para a velha incúria portuguesa e para o Museu de Macau, onde as peças portuguesas mais antigas são do século XIX...

Nas ruas de Malaca respira-se o ar tranquilo do Macau de há trinta anos. Poucos arranha-céus, poucos automóveis, casas comerciais modestas. Muitos edifícios com arcadas, colunas e florões como os da arquitectura colonial que ainda se vê em Macau e em Goa, mas já tão raramente.

A autora continua a descrição da cidade, do espaço público, das pessoas, caracterizando-a como "um pequenino mundo multiracial" (Batalha, 1981:30). E, "Saindo do centro da cidade e a uns vinte minutos de riquexó-triciclo - o mais prático meio de transporte - chega-se ao bairro dos portugueses" (Batalha, 1981:30). O bairro, que "parece uma aldeia de pescadores", é descrito como composto de "casinhas de madeira, de um só andar, com o seu quintalório à frente, onde por vezes retouça um cabrito ou esgaravatam galinhas" (Batalha, 1981:30). Anota o processo de modernização nos materiais usados nas casas tradicionalmente e agora (anos 80), melhorias nas moradias. A voz dos seus informantes é visível na assumpção crítica de um ambivalente processo turístico em curso (Batalha, 1981:33-34):

A um dos missionários ouvimos palavras de censura ao que chamou a segregação, ou pelo menos a estratificação, duma comunidade transformada em peça de museu. E certamente é como curiosidade antiga e rara que figura nos itinerários das agências de turismo, porque vimos 
autocarros de turistas em constante entrar e sair do Settlement. Para nós, portugueses europeus, era um tanto chocante ver toda aquela pobreza servir de espectáculo aos olhos de estranhos. Mas aos residentes, pessoas aparentemente sem complexos, não parecia isso incomodar minimamente. E que o bairro é uma curiosidade antiga $e$ rara, isso é. Desde os históricos nomes portugueses das ruinhas $[\ldots]$ até ao aspecto físico e à língua dos habitantes, tudo é diferente do que se vê na cidade.

A valoração global do espaço e o uso de uma adjectivação que qualifica o bairro com recurso a diminutivos - "ruinhas" desvenda algum enviesamento paternalístico.

No texto sobre a "Situação e Perspectivas do Português e dos Crioulos de Origem Portuguesa na Ásia Oriental (Macau, Hong Kong, Malaca, Singapura, Indonésia)" publicado em 1985, Graciete Batalha analisa, entre outros, o contexto do crioulo de Malaca. As notas de contextualização sociolinguística são importantes. Interessante aqui, para além de mapear uma comunidade "segregada" e dispersa pela cidade,

A segregação racial, relacionada com o euro-asianismo e a religião, deve ter sido no passado um dos motivos mais fortes para a manutenção da língua portuguesa. Seria a princípio - depois da queda dos portugueses - uma espécie de língua secreta, só conhecida dos que possuíam a perigosa herança, e mais tarde de outros euro-asiáticos de várias procedências, igualmente pobres, igualmente segregados, que acharam acolhimento nos Kampongs dos serâni (ou nazarenos) e se fizeram herdeiros das mesmas tradições. Não quer isto dizer quer todos os membros da comunidade vivam concentrados nos Kampongs. Podem viver onde quiserem, mas só os que desfrutam de situação económica mais desafogada têm possibilidades de viver no centro da cidade (Batalha, 1985:300).

Sobre a evolução local da língua, denota a autora que "não difere muito da que pude registar há 9 anos [1974], quando passei 
oito dias entre o hospitaleiro povo do Kampong Portugis" (Batalha, 1985:300). Contudo, observa que estará em curso uma

maior aproximação vocabular com o português normal $e$ que é, sem dúvida, resultado do grande número de portugueses ou pessoas de língua portuguesa que têm visitado Malaca nos últimos anos, quer como turistas, quer como investigadores (Batalha, 1985:300).

A visibilidade local do processo turístico e os possíveis impactos linguísticos ao nível de interacções interpessoais entre residentes $e$ turistas falantes de português são alvo de referência, ainda que não aprofundada. Sobre o espaço físico do Bairro Português, são anotadas pela linguista algumas transformações (físicas e sociais) no período decorrido entre 1974 e 1983. Justifica-se uma citação alargada das palavras da autora (Batalha, 1985:301-302), reproduzindo aspectos que ajudam a fixar a representação traçada pela observadora (os sublinhados são acrescentados):

Há nove anos, a impressão de quem visitava o bairro era de pobreza prevalecente. Pobreza, não miséria, note-se. Nada de esquálido, nada de trágico. As numerosas crianças que brincavam pelas ruas e modestos quintais estavam mal vestidas mas eram saudáveis, risonhas, prontas a entrar em conversa com estranhos e sobretudo a cantar, e com que desenvoltura e alegria! O mesmo se podia dizer dos adultos. Contudo, havia muito desemprego, muito analfabetismo, muita promiscuidade de famílias vivendo aglomeradas em casas pequeníssimas. [...] Presentemente, [...] as diferenças são notáveis. A pobreza é menos evidente. Muitas casinhas têm a sua TV a cores e o seu telefone, coisas que não se viam há 9 anos. O desemprego diminuiu com a abertura em Malaca de fábricas, hotéis e restaurantes // onde rapazes e raparigas se vão colocando. O próprio bairro, que só tinha um barracão a servir de café, tem agora três restaurantes (com nome português, note-se: "Restaurante Português", "Aleluia" e "San Pedro", modestos mas muito 
procurados pelos seus pratos à portuguesa. "À portuguesa" de Malaca, porém muito saborosos.

A terminar, redige um comentário valorativo de alinhamento com a Missão Portuguesa - em tonalidade algo eurocêntrica, senão mesmo apocalíptica (Batalha, 1985:302):

Esta presença [portuguesa], mantida há séculos apenas pelos Missionários Portugueses, pode ter recebido um golpe fatal com a supressão da jurisdição da Diocese de Macau sobre os descendentes de Malaca e Singapura. A separação deu-se por decreto da Santa Sé de 27 de Maio de 1981, ao que parece com o acordo de Portugal e contra os anseios $e$ os apelos das comunidades em causa. Contudo, os nossos missionários ainda não desertaram. Foi-lhes permitido continuar no seu posto e a Diocese de Macau continua a prover à sua manutenção. Até quando? É difícil de prever, mas é mais que certo que a presença viva de Portugal permanecerá com eles. Mas, por enquanto ainda, o apego sentimental à Pátria-Mãe é muito vivo. Há crianças cujo sonho máximo é visitar um dia Portugal e que coleccionam todas as pequenas coisas portuguesas que lhes dêem: postais, selos, moedas.

É inegável a riqueza etnográfica do relato de Graciete Batalha, não tanto pelo que revela do grupo Kristang, mas sobretudo pelo que revela do seu próprio olhar de observadora presa a uma subjectividade de colonialismo tardio; que parece, não obstante, estar na transição de dois tempos e modos de produção de conhecimento, o tempo colonial e o pós-colonial.

\section{Balanço em aberto e tópicos para discussão}

A praxis científica de Graciete Batalha operou a construção de um capital científico a partir do magistério científico de Coimbra, o que a levaria ao reconhecimento internacional $e$ à disseminação do seu trabalho no século XX. Ou seja, um claro 
exemplo da atuação do modelo de uma Filologia perene e o ícone do "laboratório de bata branca" que Bernardes (2015) traça para caracterizar o edifício científico arquitetado por Carolina Michaelis e alargado por Manuel Paiva Boléu (Homenagem, 1992).

Graciete Batalha, como praticante do INQUÉRITO LINGUÍSTICO BOLEO (ILB) ${ }^{6}$ assume-se como uma professora que complementa o seu magistério no espaço de administração colonial do Oriente - Macau - com a investigação filológica e linguística.

[O] vírus do inquérito linguístico, tão sabiamente inoculado nos seus licenciados pelo Mestre de Filologia Portuguesa [Paiva Boléo] [...] não me permitiu contactar com um dialecto da nossa língua sem inquirir pessoalmente até que ponto se mantinha viva a fala duma comunidade "portuguesa" (Batalha, 1981:25).

Estamos perante um gradual processo de reconhecimento científico. Por um lado a visibilidade de Graciete na Ásia (Macau), por outro lado sua inicial invisibilidade em Portugal, mas com reconhecimento científico na Europa dos filólogos e linguistas, documentado pelos artigos publicados sobre a utilização prática do ILB no Oriente - em Macau e em Malaca (Batalha, 1985).

Recorde-se ainda a correspondência trocada com o Professor Manuel Paiva Boléo, da Universidade de Coimbra, mestre da autora, que a incentivou a continuar a pesquisa de crioulo de português em territórios asiáticos, memória incorporada no Catálogo da Exposição do Instituto Cultural de Macau, ao reproduzir algumas dessas cartas $^{7}$ (Batalha, 1995). Em 1957,

${ }^{6}$ É preciso fixar o empreendimento científico de Manuel de Paiva Boléo: a criação e o uso do Inquérito Linguístico Boléo - ILB, O estudo dos dialectos e falares portugueses. Um inquérito linguístico, e o apêndice a $O$ interesse científico da linguagem popular, e o conjunto de estudos disseminados na Revista Portuguesa de Filologia que vai dando conta das teses, dos trabalhos e dos estudos comparativos que Paiva Boléo foi empreendendo.

7 A realidade do patoá - crioulo de raiz portuguesa usado em Macau, nomeadamente na família do seu marido - impulsionou Graciete Batalha a 
Graciete publica no Boletim de Filologia, do Centro de Estudos Filológicos de Lisboa, na época dirigido por Lindley Cintra, o seu trabalho intitulado "Para uma interpretação do topónimo Macau". Será no ano seguinte - 1958 - que a Universidade de Coimbra lhe abre as páginas da Revista Portuguesa de Filologia, para sair a público o "Estado actual do dialecto macaense".

A autora troca longa correspondência com o Professor Manuel Paiva Boléo que a incentiva a continuar a pesquisa de crioulos de português em territórios asiáticos, facto que o Catálogo da Exposição do Instituto Cultural de Macau nos dá conta ao reproduzir algumas dessas cartas $^{8}$ (Batalha, 1995). É exatamente essa especificidade do seu trabalho - levantamento linguístico no terreno, anotações, sistematização - com as respectivas disseminação e publicação científica que a transforma em membro de uma comunidade internacional. Em 1957, publica no Boletim de Filologia, do Centro de Estudos Filológicos de Lisboa, na época dirigido pro Lindley Cintra, o seu trabalho intitulado «Para uma interpretação do topónimo Macau». Será no ano seguinte - 1958 que a Universidade de Coimbra lhe abre as páginas da Revista Portuguesa de Filologia, para sair a público o "Estado actual do dialecto macaense".

escrever "ao seu antigo mestre [...] o Professor Doutor Manuel de Paiva Boléo, em carta de 09 de Agosto de 1950, manifestando-lhe a vontade de contribuir para a actualização do estudo da língua portuguesa no Extremo Oriente. Algum tempo depois, a 09 de Abril de 1951, o Professor Paiva Boléo respondia-lhe, encorajando-a a iniciar esses estudos. E, 1953, já o Professor Paiva Boléo fazia referência nas suas cartas ao primeiro trabalho da Dra Graciete Batalha sobre a linguagem de Macau [...]" (Batalha, 1995:7).

8 A realidade do patoá - crioulo de raiz portuguesa usado em Macau, nomeadamente na família do seu marido - impulsionou Graciete Batalha a escrever «ao seu antigo mestre [...] o Professor Doutor Manuel de Paiva Boléo, em carta de 09 de Agosto de 1950, manifestando-lhe a vontade de contribuir para a actualização do estudo da língua portuguesa no Extremo Oriente. Algum tempo depois, a 09 de Abril de 1951, o Professor Paiva Boléo respondia-lhe, encorajando-a a iniciar esses estudos. E, 1953, já o Professor Paiva Boléo fazia referência nas suas cartas ao primeiro trabalho da Dra Graciete Batalha sobre a linguagem de Macau [...]" (Graciete Batalha, 1995:7). 
O reconhecimento internacional do seu trabalho certamente pela disseminação dessas prestigiadas publicações apoiadas pelo Instituto de Alta Cultura do Estado português torna-se visivel nas cartas trocadas com Luiz Ferraz, Alan Baxter, R. W. Thompson, David Jackson, John Holm, Edgar Knowlton que repousam no espólio oferecido em 1995 à Biblioteca Central de Macau (Batalha, 1995).

Graciete Batalha constitui um focus de análise trabalho para cruzamos territórios disciplinares onde história da ciência e dos seus atores constituem pontos de iluminação para o binómio de género e história da ciência em contextos coloniais (Sarmento, 2008; Silva, 2008), iluminando sombras metropolitanas sobre práticas científicas com ligação à comunidade científica de formação - a Faculdade de Letras e o património de Escola científica da genealogia científica criada entre Carolina Michaelis de Vasconcelos e Manuel de Paiva Boléo (Nunes, 2007; Michaelis, 2015; Delile, 2015).

Estamos em pleno século XX da sociedade portuguesa, entre um recorte de ideia de construção de Europa pela via científica filologia $e$ a linguística $-e$ a gestão cultural $e$ científica do vasto império colonial, com territórios africanos e espaços na Ásia, conclaves encaixados em outras dimensões civilizacionais, culturais e mentais.

Pretendemos argumentar que a filóloga e discípula de Manuel de Pavia Boléu faz parte do elo de genealogia científica da comunidade científica que Carolina Michaelis de Vasconcelos primeira professora catedrática da Universidade de Coimbra - fez nascer, num contexto de prática científica de colecionar estudos e levantamentos filológicos centrados na construção $e$ na formatação linguística na Nação, no quadro mental da Europa da transição de final do século XIX para o século XX.

Nesse contexto, emerge uma figura feminina que se assume pelas suas facetas de investigadora $e$ de fazedora de redes científicas. Deixemos algum discurso direto para podermos sentir o pulsar de Graciete Batalha no Oriente colonial português, seguindo António Aresta. 
Em jeito de confidência, anotou no seu diário: "Como ninguém mais tem estudado o crioulo macaense nos tempos modernos e como o faço de modo cauteloso, cingindo-me aos meus limites, parece que os meus trabalhos, publicados na Revista Portuguesa de Filologia, têm sido bem aceites no estrangeiro. Em Portugal não sei, ninguém se pronuncia. Santos de casa... Aqui tenho, pois, uma carta do Hancock e dum outro Prof., Edgar C. Polomé, ambos da Universidade de Texas nos Estados Unidos, convidando-me para participar numa publicação que vão lançar, Journal of Creole Studies, como "consulting editor' e membro do corpo editorial. (...) Antes disso já tinha recebido uma carta mais informal sobre o assunto, indicando outros convidados para 'consulting editor', alguns dos quais nomes consagrados que conheço de leituras ou correspondência: Keith Whinnom, Marius Walkhoff, a quem escrevi uma vez em inglês e me respondeu em perfeito português, John Reinecke, etc.. O meu é o único nome português, certamente porque muito poucos linguistas portugueses se dedicam ao estudo dos nossos crioulos, especialmente crioulos do Oriente" (Aresta, 2011:286). ${ }^{9}$

A prova dessa sua perceção emotiva e pessoal surge-nos compaginada na citação de trabalhos de Graciete Batalha em resultados de agendas de matriz internacional, num processo global de trocas e de circulação de ciência, em meandros geográficos de Ásia - Europa - América. Em breve nota de obituário, Holm (1994) rasga o cenário de diferentes perfis de Graciete Batalha em terras da Ásia, em périplo geográfico alargado que sempre implicou o (eterno) retorno a Macau, ainda sob a administração do Estado português, já em configuração de democracia.

9 António Aresta segue o Diário de Graciete Batalha, Bom dia S'tora, pp.112113. 
Encontra-se referenciada $e$ usada como informação científica em território de sinalizar encontros históricos de culturas (Czopek, 2014), em agenda de diálogos patrimoniais e de "encontros culturais" como é o caso de Macau como "cultural Janus" (Cheng, 1999) e de análise de crioulo em contexto histórico comparado (Granda, 1968) ou com sua presença de citação em Gradual Creolization (2009). Recentemente os seus textos e a sua história de vida ${ }^{10}$ permitiram a entrada nas referências bibliográficas e em narrativa científica de texto de tese de doutoramento, sob a supervisão das Universidades do Algarve $e$ de Macau (Alves, 2014).

Essa incursão pela área conceitual de "history of science and gender studies" abriu novas perspetivas de trabalho, criou-nos alguns paradoxos para visões futuras e reiterou-nos a importância de desconstruir as narrativas históricas científicas cristalizadas, a dos visíveis, para colocar sobre a bancada de laboratório os(as) (in)visíveis oficias. Em debate, em aberto, temos sem dúvida o papel que a prática científica das periferias coloniais pode ter desempenhado na construção científica de campos disciplinares, neste caso a filologia/linguística. É nesse contexto científico que temos que inserir a figura de "mulher de bata branca" da filologia, Graciete Nogueira Batalha, porque utilizou a instrumentação científica - ILB - no seu trabalho de campo, em território colonial português da Ásia. Pretendemos ver nela uma herdeira intelectual indireta, de comprometimento científico, de Carolina Michaelis, uma vez que esse nome esteve, seguramente, muitas vezes nos bancos dos anfiteatros da Faculdade de Letras da Universidade de Coimbra dos anos quarenta. Carolina, uma referência científica para Manuel de Paiva Boléo, que, em 1929, vai em missão científica financiada para a Universidade de Hamburgo ${ }^{11}$, pode aí

\footnotetext{
${ }^{10}$ A publicação do diário Bom dia S'tora permitiu descobrir diversificadas narrativas e etnografias de um professor e uma investigadora em terras de administração colonial, em diferentes configurações político-ideológicas do Estado português.

${ }^{11}$ Em 1929, é criada a Junta de Educação Nacional que teve como principal impulsionador Celestino da Costa e que visava a modernização da Ciência em
} 
desenvolver o trabalho preparatório do Inquérito Linguístico que veio a assumir o seu nome: Boléo. E de Coimbra, por via da transmissão de ensino e da investigação empírica, foi até Macau e Malaca - e outros pontos da Ásia Oriental. Foi esse trabalho que deu notabilidade científica, poder social e político a Graciete Batalha.

Ao ser-lhe outorgado o reconhecimento de uma carreira científica, de nível internacional, essa circunstância nos faz pensar em diferentes formas de construir as redes de transmissão de poder de mimetismo (e de obediência disciplinar) que enquadram a imagem de uma professora do Liceu, localizada em espaço colonial! O teatro das sombras foi abalado por holofotes inovadores (Sarmento, 2008) e despontaram cenários ocultos que ajudarão a construir novas facetas de história da ciência, nesse caso vertente das ciências sociais e humanas, talvez laboratório de ideias para outras experimentações em impérios coloniais vs. teatros de sombras, com instituições, atores e práticas científicas ainda por iluminar.

Para uma micro-história do discurso científico: resgatando as (in)visibilidades?

Olhada a partir da Biblioteca Nacional de Portugal, com uma grelha de leitura que problematiza relações entre ciência $e$ ideologia, encontramos, até quase à contemporaneidade, um puzzle retórico que coloca Malaca numa espécie de "lugar de memória" da Nação Expansionista; um lugar nostálgico do Império, preso entre luzes e sombras.

Após 1974 e a queda do regime salazarista, as mudanças académicas efectivam-se, e existem alguns novos (ou renovados)

Portugal. O grupo de investigação CEHFCi tem desenvolvido vários trabalhos nessa matéria, e devemos aqui sinalizar a tese de Doutoramento de Quintino Lopes, em História e Filosofia da Ciência, na Universidade de Évora (a defender em 2017) intitulada "A Junta de Educação Nacional (1929-1936) traços de europeização na investigação científica em Portugal ". 
lugares de produção científica de onde se olha a Ásia. ${ }^{12}$ Até às rupturas epistemológicas que acontecem no fim dos anos 80 e no início da década de 1990, parece existir uma continuidade de produção académica na sombra de instituições e actores regulados pelo Estado Novo. Nos anos 1990, dão-se relevantes viragens críticas na academia. Os mesmos anos 90 tornam visíveis outros aspectos: nos anos 90, como nos anos 40 do século XX, as agendas comemorativas políticas balizam, ou pelo menos influenciam, as agendas de investigação e divulgação científica, (1994 - Lisboa, Capital Europeia da Cultura - e Expo 1998), ressuscitando as temáticas do mar e dos oceanos; e desvendando retóricas nostálgicas, recicladas com uma nova roupagem, que parecem reactualizar temas antigos. Olhada à lupa antropológica $e$ histórica, desbravamos com Graciete Batalha uma micro-história das práticas de ciência nos tropicais Estreitos de Malaca. No cenário de interdisciplinaridade em que vivemos hoje, esse parecenos um dos terrenos para a antropologia, a história e os estudos de género desbravarem em conjunto.

\section{Referências bibliográficas}

AlATAS, Syed Farid. Alternative Discourses in Asian Social Science: Responses to Eurocentrism. New Delhi, Sage Publications, 2006.

AlVES, Carlos Miguel Botão. A Sabedoria Oriental na Obra Poética de Antero de Quental e Ensaística de Manuel da Silva Mendes. Tese (Doutorado em Literatura) - Universidade do Algarve, Macau, 2014.

ANTUNES, Luis Pequito. Maria Corinta Ferreira (1922-?) "naturalista do Museu Dr. Alvaro de Castro...". HoST - Journal of History of Science and Technology, vol. 10, $\mathrm{n}^{\circ}$ 1, julho 2016, pp.103-124. DOI: 10.1515/host-2016-0005

12 Instituto de Investigação Científica e Tropical, Instituto de Estudos Orientais (UCP), o Centro de História de Além-Mar (FCSH), o Centro de Estudos sobre o Sudeste Asiático (CEPESA), e o recentemente criado Instituto Confúcio, da UL (recentemente criado, e procurando estreitar relações e investigação com a China). As Fundações Calouste Gulbenkian, Fundação Oriente, o recente Museu do Oriente, e o Centro Científico e Cultural de Macau completam o mosaico. 
ARESTA, António. A Professora Graciette Batalha. Administração n 51, vol. XIV, 2001-1. ${ }^{\circ}$, pp.277-294.

ARESTA, António. A professora Graciete Batalha. Macau, Instituto Internacional de Macau, 2010.

BARATA, Óscar Soares. Os Noventa Anos do ISCSP: Dos Estudos Coloniais ao Desafio do Sul. ISCSP: 90 anos. Lisboa, ISCSP, 1996, pp.23-37.

BATALHA, Graciete N. O Inquérito Linguístico Boléo em Malaca: O Chão de Padre e Seus Moradores Portugueses. Separata de Biblos, LVII, Coimbra, Faculdade de Letras/Universidade de Coimbra, 1981, pp.25-63. [Homenagem a M. Paiva Boléo]

BATALHA, Graciete N. Situação e perspectivas do português e dos crioulos de origem portuguesa na Ásia Oriental (Macau, Hong Kong, Malaca, Singapura, Indonésia). In: Congresso sobre a Situação Actual da Língua Portuguesa na Mundo. Actas..., vol. I, Lisboa, Instituto de Cultura e Língua Portuguesa, 1985, pp.287-303.

BATALHA, Graciete. Malaca: o Chão de Padre e os Seus Moradores 'Portugueses'. Separata de Biblos LVII. Macau, Imprensa Nacional, 1986 [1981].

BATALHA, Graciete. Bom dia, s'tora!: Diário duma professora em Macau. Colecção Rua Central. Macau, Instituto Português de Macau, 1991.

BAXTER, Alan. Introdução. In: RÊGO, A. da Silva. Dialecto Português de Malaca e outros escritos. Lisboa, Comissão Nacional para as Comemorações dos Descobrimentos Portugueses, 1998, pp.11-44.

BERNARDES, José António Cardoso. A Filologia perene e o ideal da bata branca. In: CONDÉ, Valéria Gil; MONGELLI, Lênia Márcia; VIEIRA, Yara Frateschi (orgs). Carolina Michaelis de Vasconcelos: Uma Homenagem, São Paulo, FFCH-USP, 2015, pp.47-66.

BLICKENSTAFF, Jacob Clark. Women and science careers: leaky pipeline or gender filter? Gender and Education, vol. 17, n 4, Taylor \& Francis Ltd., outubro 2005, pp. 369-386.

ChEng, Christina Miu Bing. Macau: A Cultural Janus. Hong Kong University Press, 1999. 
cadernos pagu (49), 2017:e174911 Ema Ribeiro Pires e Maria de Fátima Nunes

CONDÉ, Valéria Gil; Mongelli, Lênia Márcia; VIEIRA, Yara Frateschi (org.). Carolina Michaëlis de Vasconcelos: uma homenagem. São Paulo, NEHiLP/FFLCH/USP, 2015 [http://www.usp.br/nehilp/livros/Carolina_Michaelis.pdf].

CZOPEK, Natalia. Os portugueses em Macau no século XVIII. Considerações sobre um encontro de culturas. Romanica Cracoviensia, 14, 2014, pp.153-167. [consultável em www.ejournals.eu/Romanica-Cracoviensia].

Delile, Maria Manuela Gouveia. Carolina Michaellis de Vasconcelos: um perfil. In: CONDÉ, Valéria Gil; MONGELLI, Lênia Márcia; VIEIRA, Yara Frateschi (org.). Carolina Michaëlis de Vasconcelos: uma homenagem. São Paulo, NEHiLP/FFLCH/USP, 2015, pp.121-144.

GRACIETE Byatalha. Catálogo da Exposição Fotobibliográfica e Documental: 23 de Novembro a 9 de Dezembro. Coord. Jorge de Abreu Arrimar. Trad. Chu Pan, Tang Yuk Ling. Macau, Ed. Biblioteca Central de Macau, 1995.

Gornick, Vivian. Women in Science. Nova Iorque, The Feminist Press, 2009.

GRANDA, Gérman de. La tipologia "criolla" de dos hablas del área linguística hispanica. Thesaurus. Boletim Del Institutto Caro $Y$ Cuervo, Tomo XXIII, nº 2, 1968, pp.194-205.

HISTÓRIA da língua portuguesa. Manuel De Pavia Boleo. - Biografia. [http://cvc.instituto-camoes.pt/hlp/biografias/pboleo.html]

Holm, John. In Memoriam Graciette Nogueira Batalha. PAPIA: Revista Brasileira de Estudos Crioulos e Similares, vol. 3, 1994, pp.106-197. [http://www.revistas.fflch.usp.br/papia/article/view/1767/1578]

Homenagem ao Doutor Manuel de Paiva Boléo. Biblos, 58, 1982, pp. 512-16; Biblos, 68, 1992, pp.646-49.

LAMPHERE, Louise; RAgONÉ, Helena; ZAVELla, Patricia. Introduction. In:__. (eds.) Situated Lives: gender and culture in everyday life. Londres, Routledge, 1997, pp.1-19.

LOPES, Maria Margaret. Gender, Collecting practices, Museums. HoST Journal of History of Science and Technology, vol. 10, $\mathrm{n}^{\circ} 1$, julho 2016, pp.1-9. ISSN 1646-7752, DOI:10.1515/host-2016-0001 
NUNES, Maria de Fátima. Carolina Michaelis de Vasconcelos - a construção científica nas Ciências Humanas na esfera do Positivismo. In: HENRIQUES, Fernanda (ed.) Género, Diversidade e Cidadania. Colibri, Chideus, 2007, pp.89-100.

RÊGO, A. da Silva. O dialecto português de Malaca e outros escritos. Lisboa, Comissão Nacional para as Comemorações dos Descobrimentos Portugueses, 1998 [1942].

SARMENTO, Clara (ed). Women in the Portuguese Colonial Empire: the theatre of Shadows. Cambridge Scholar Publishing, 2008.

SelbaCH, Rachel; CARDoso, Hugo C.; Berg, Margot van den (ed.). Gradual Creolization: Studies Celebrating Jacques Arends. Amsterdam; Philadelphia, Ed. John Benjamin B.V., 2009.

SiLVA, Cristina Pinto da. Battle Against Silence: the diary fo Graciette Nogueira Batalha, a teacher in Macao. In: SARMENTO, Clara (ed). Women in the Portuguese Colonial Empire: the theatre of Shadows. Cambridge Scholar Publishing, 2008, pp.145-152.

STRATHERN, Marilyn. O gênero da dádiva: problemas com mulheres e problemas com a sociedade na Melanésia. Campinas-SP, Editora da Unicamp, 2006 [1988]. 